June 2019

\title{
"The gender gap in informal child care: theory and some evidence from Italy"
}

Francesca Barigozzi, Helmuth Cremer and Chiara Monfardini 


\title{
The gender gap in informal child care: theory and some evidence from Italy*
}

\author{
Francesca Barigozzi $^{\dagger} \quad$ Helmuth Cremer $^{\ddagger} \quad$ Chiara Monfardini $^{\S}$
}

May 2019

\begin{abstract}
Our model studies couples' time allocation and career choices, which are affected by a social norm on gender roles in the family. Parents can provide two types of informal child care: basic care (feeding, changing children, baby-sitting) and quality care (activities that stimulate children's social and cognitive skills). We obtain the following main results. Traditional mothers provide some informal basic care, whereas career mothers purchase full time formal basic care in the market. Informal basic care is too large and the group of career mothers is too small because of the social norm. Informal quality care is increasing in the couple's income and is provided in larger amount by mothers. We test the model's predictions for Italy using the most recent ISTAT "Use of Time" survey. In line with the model, mothers devote more time than fathers to both basic and quality informal care; more educated parents devote more time to quality informal care than less educated parents; more educated mothers spend more time in the labor market than less educated mothers.
\end{abstract}

JEL-Classification: D13, H23, J16, J22

Keywords: Social norms, basic and quality child care, women's career choices, gender gaps.

\footnotetext{
${ }^{*}$ We are grateful to Chiara Bernardi for excellent research assistance.

${ }^{\dagger}$ University of Bologna, Email: francesca.barigozzi@unibo.it.

${ }^{\ddagger}$ Toulouse School of Economics, University of Toulouse Capitole, Toulouse, France; Email: helmuth.cremer@tse-fr.eu.

${ }^{\S}$ University of Bologna, IZA and CHILD-CCA, Email:chiara.monfardini@unibo.it.
} 


\section{Introduction}

Women's labor force participation has been increasing steadily over the last decades in all developed countries; see Goldin (2006) and (2014), Kleven and Landais (2017). Nevertheless, mothers continue to be the main providers of child care; see Paull (2008) or Ciccia and Verloo (2012). Women's career choices contribute to this outcome. As a possible reason for the persistence of child-care compatible (part-time) work many studies point to social norms shaping women's preferences over family and career; see Fortin (2015), Farré and Vella (2013), Bertrand et al. (2015), Bursztyn et al. (2017) and Kleven et al. (2018), among others. Social norms contribute to the differential sorting of men and women across occupations with women entering low pay occupations that allow for shorter working days or more flexible working hours; see Goldin (2014) and Card et al. (2016).

Two recent papers, Barigozzi et al. (2018 and 2019a) have examined the interplay between social norms, career choices and child-care decisions. In their setting fathers always enter a highcareer path while mothers can enter a high-career path or a low-career one. In the latter case mothers are "traditional" because they are able to provide some informal child care. "Career mothers" instead need to purchase full-time formal care in the market. The sorting of women across career paths is endogenous and shaped by a social norm about gender roles in the family. Via this social norm traditional mothers' informal care imposes an externality on career mothers, who feel guilt if they provide less informal care than the amount provided by the median mother in the previous generation (in Barigozzi et al. 2018); or than the average amount provided by woman in the current generation (in Barigozzi et al. 2019a). Hence, in the laissez-faire, informal care is too large and the share of career mothers is too small. This translates in inefficiently high child penalties so that inefficiency and gender inequality go hand in hand.

In the theoretical part of this paper we generalize those models to distinguish between basic child care and quality child care. Barigozzi et al. (2018 and 2019a) assume that total child care must be equal to one. In other words, a young child needs full time care so that by definition formal and informal care must add up to a constant normalized to one. We assume that this constraint applies to basic child care but not to quality care; the total level of quality child care is endogenous. To be more precise there is a trade off between leisure and quality care. We assume that the contribution of quality care to utility is larger for more productive couples. This may be a matter of preferences and/or reflect the fact that the children's benefit from receiving quality informal care increases with their parents' income or level of education; see, among others, Chiappori et al. (2017) and Doepke et al. (2019) and references within.

While we do present the optimal allocation in our economy, we otherwise focus on positive aspects. Specifically, we characterize the equilibrium (laissez faire) solution and examine its properties focusing on the couples' key choice variables. We show that mothers devote more 
time than fathers to both basic and quality informal care and that time devoted to quality child care by both mothers and fathers is increasing in the family income. In addition, career mothers spend more time in the labor market than traditional mothers and time devoted to basic child care by mothers is decreasing in the family income.

These results directly translate into testable implications, which we confront with the data in the second part of the paper. We use the most recent available Italian ISTAT "Use of Time" survey, carried out in 2013, and consider the following time categories: informal child care, split up into basic and quality child care, household work and market work. This categorization follows Barigozzi et al. (2019b) who study how individuals of different gender, age, education and background allocate their time among several activities across a time span of more than 10 years (2002-2013).

The descriptive statistics reported in the tables along with some tests and a simple regression analysis suggest that our first three predictions are consistent with the data. The fourth prediction, on the other hand, namely that time devoted to basic child care by mothers is decreasing in the family income is not confirmed. However, we argue that this is likely to be an artifact of the classifications adopted in the data. Specifically, we consider only the primary activity that is reported and some basic child care is likely to be lumped together with household work. This conjecture is vindicated by the fact that a revisited version of Prediction 4, namely that "total time devoted to basic child care and household work by mothers is decreasing in the family income" is consistent with the data. ${ }^{1}$

Overall the empirical results show that Italian mothers provide more informal care and much more household work than their partners; for a more detailed analysis of those and other gender gaps characterizing Italian families see Barigozzi et al. (2019b). Our theoretical model provides a possible explanation of the observed gender gaps in informal care provision shaped by a social norm on gender roles in the family.

\section{The model}

The model builds on Barigozzi et al. (2018, 2019a). Consider a population of couples with children, the size of which is normalized to one. Each couple consists of a mother ' $m$ ', a father

\footnotetext{
${ }^{1} \mathrm{~A}$ second reason why, in the sample, time devoted to basic child care by mothers is not decreasing in the family income is related to the fact that we use education as a proxy for women's career prospects. The $20 \%$ of working mothers are school teachers in Italy. School teachers are "highly educated" and thus are considered "career mothers" in the sample. However school teachers represent "traditional mothers" in our theoretical model because they typically have no career prospects but enjoy the flexibility to provide more informal basic care than mothers in other full-time jobs. This implies that the average time devoted to basic informal child care by "career mothers" in the sample is overestimated.
} 
' $f$ ', and a given number of children. Couples choose their career path, their consumption, and the amount of basic informal child care and quality informal child care provided to their children.

There exist two types of career paths (indexed by $j$ ). In the less demanding, low-career path, $j=\ell$, working hours are flexible and individuals can freely choose how much time to spend in the labor market. The time not spent at work can be used for basic child care $c_{i}$, where $i=f, m$. Hence, the low-career path can be seen as a part-time work where the number of working hours are chosen by the parent. Basic child care corresponds to the time devoted to the basic needs of children: feeding, food preparation, washing, changing children and baby-sitting. In the full engaging high-career path, $j=h$, individuals have to work the entire working part of the day so that there is no time for basic child care. We also assume that, both in the highand in the low-career path, parents are free to allocate part of their leisure time to quality care: helping children with homework, reading books, playing games with them and so on. To sum up, couples face two time constraints: basic child care affects the allocation of parents' time during the working-day. Given that children must be taken care of the whole working day that we normalize to one, we have that, for each couple, $1=c_{f}+c_{m}+c_{p}$, where $c_{p}$ is formal basic child care purchased by parents in the market. In addition, a part of the available per-day leisure time, $\bar{L}$, can be devoted by each parent to quality child care so that we have: $\bar{L}=L_{i}+d_{i}$, $i=f, m$, where $L_{i}$ is parent's $i$ leisure time and $d_{i}$ is quality child care.

Both jobs pay the wage rate $y$, but the high-career path comes with additional future earning possibilities $q_{i}$. We let $q_{f} \in[0, Q]$ and $q_{m}=\alpha q_{f} \in[0, \alpha Q]$, with $\alpha \in(0,1]$. An $\alpha<1$ captures pure discrimination: unequal pay for equally qualified workers, as it continues to be documented in nearly all developed countries. ${ }^{2}$ Observe that while $\alpha<1$ adds a measure of realism, it will not be essential for our results that all continue to hold when $\alpha=1$. Future revenue $q_{f}$ is distributed according to $F$ with density $f$. Future earning opportunities are perfectly correlated in a couple. Consequently, there is a single level of $q_{m}$ associated with each level of $q_{f} .{ }^{3}$

Child care bought in the private market is denoted by $c_{p}$. The latter costs $p$ per unit of time. We let $p=y$, meaning that the current salary of one member in the couple exactly covers the costs of buying full-time child care on the private market. ${ }^{4}$ When parents enter a flexible job their salary decreases proportionally to the time devoted to basic care. Informal and private

\footnotetext{
${ }^{2}$ The parameter $\alpha$ generates the unexplained component in the Oaxaca-Blinder decomposition of the GWG; see Blinder (1973) and Oaxaca (1973). Equation (5) below presents the decomposition of the GWG obtained in our model.

${ }^{3}$ Assortative mating is commonly observed and has been increasing over the last decades; see Chiappori et al. (2017) and references within.

${ }^{4}$ This assumption is simply a normalization that has no relevance for our results. Without it we would obtain a term proportional to $(p-y)$ in the first-order conditions with respect to child care. This would affect the equilibrium levels of child care but otherwise all other results are not affected.
} 
basic care constitute a family public good and its value to the parents is given by:

$$
G\left(c_{f}, c_{m}, c_{p}\right)=v\left(c_{f}+c_{m}\right)+\beta v\left(c_{p}\right),
$$

where $v^{\prime}>0, v^{\prime \prime}<0$ and $v(0)=0$. Care provided by the father and mother are thus perfect substitutes while informal and private care are imperfect substitutes, with private care being (weakly) less welfare-enhancing than informal care, $\beta \in(0,1] .^{5}$

Quality child care cannot be purchased in the market and is only provided by the parents. It represents another family public good whose value to the parents is given by:

$$
\rho_{i}(q) v_{d}\left(d_{i}\right), i=f, m \text {. }
$$

As before $v_{d}^{\prime}>0, v_{d}^{\prime \prime}<0$ and $v_{d}(0)=0$. In addition $\rho_{i}(q)$ denotes how important are the children's cognitive achievements and progress for parent- $i$, with $\rho_{i}^{\prime}(q)>0$ : the relevance of this public good is increasing in the couple's future career prospects and is gender-specific. ${ }^{6}$ Mothers attribute more importance to children's socialization than fathers and report larger parental role responsibilities towards cognitive progress and children's achievements (Yeung et al. 2001, and Craig 2006 among others); hence we assume $\rho_{f}(q) \geq \rho_{m}(q) \forall q$.

Following Akerlof and Kranton (2000; 2010), individuals may suffer a disutility by deviating from the social categories that are associated with their identity (that is, an individual's sense of self), which causes behavior to conform to these norms. We assume that individuals desire to conform to the behavior of the group they belong to, namely the behavior of women for mothers and the behavior of men for fathers. Mothers feel guilt if they provide less informal basic care than the average amount of care provided by woman in the society. ${ }^{7}$ Fathers, by contrast, suffer from social stigma when they devote more time to informal basic care than the average amount of time devoted to care by man in the society. ${ }^{8}$

The social norm cost for mothers is given by $\gamma_{m}\left(\max \left\{0 ; \bar{c}_{m}-c_{m}\right\}\right)$, where $\bar{c}_{m}$ is the average time spent in basic child care by mothers in the society. For fathers, it is given by $\gamma_{f}\left(\max \left\{0 ; c_{f}-\right.\right.$ $\left.\bar{c}_{f}\right\}$ ), where $\bar{c}_{f}$ is the average basic time spent with children by fathers. The parameter $\gamma_{i} \in[0,1]$, $i=f, m$, reflects the costs of norm deviations.

\footnotetext{
${ }^{5}$ See, for instance, Gregg et al. (2005), Bernal (2008), and Huerta et al. (2011).

${ }^{6}$ Given that career prospects are perfectly correlated in the couple, without generality loss, we consider the following transformation $\tilde{\rho}_{f}(\alpha q)=\rho_{f}(q)$.

${ }^{7}$ The psychology literature points out that social norms on gender roles may cause mothers who work full-time to feel guilt when delegating the care of their children to others; see, Guendouzi (2006), Rotkirch and Janhunen (2010) and Rose (2017), among others.

${ }^{8}$ See, as an example, Haas and Hwang (2019) and references within. For a general overview see "Paternity Leave: The Rewards and the Remaining Stigma" The NYT, Nov. 7, 2014; available at https://www.nytimes.com/2014/11/09/upshot/paternity-leave-the-rewards-and-the-remaining-stigma.html.
} 
Apart from basic and quality informal care, each parent derives utility from consumption of a numeraire commodity $x_{i}$ and from leisure time $L_{i}=\bar{L}-d_{i}$ according to the function $v_{L}\left(\bar{L}-d_{i}\right)$, with $v_{L}^{\prime}>0, v_{L}^{\prime \prime}<0$ and $v_{L}^{\prime}(0)=0$.

The timing of couples' decisions is as follows: first, parents choose their career path and then, in the second stage, they choose consumption and the amount of child care (be it formal or informal). Parents act cooperatively and maximize the sum of their utilities:

$$
\begin{aligned}
W & =x_{m}+x_{f}+G\left(c_{f}, c_{m}, c_{p}\right)+\rho_{m}(q) v_{d}\left(d_{m}\right)+\rho_{f}(q) v_{d}\left(d_{f}\right) \\
& +v_{L}\left(\bar{L}-d_{m}\right)+v_{L}\left(\bar{L}-d_{f}\right)-\gamma_{m}\left(\max \left\{0 ; \bar{c}_{m}-c_{m}\right\}\right)-\gamma_{f}\left(\max \left\{0 ; c_{f}-\bar{c}_{f}\right\}\right) .
\end{aligned}
$$

\subsection{Couple's optimization}

We first analyze the choice of child care activities for a given career path. Then, by proceeding backward, we consider the choice of career path made by the couple. This allows us to determine the average basic child care provided in the society and thus to define the cost of the social norm both for fathers and for mothers. We consider only decisions made at the second stage by the couples that turn out to be relevant for our analysis, namely the couples where (i) only the father enters the high-career path while the mother enters the flexible job market (traditional couples), and those where (ii) both parents take up the high-career path; see Appendix A.1 for the dominated couples' decisions. ${ }^{9}$

Traditional couple. We denote welfare of this couple by $W_{h \ell}$, where the first subscript refers to the father's career choice and the second subscript refers to the mother's career choice. Since the father took up the high-career path he is not able to provide basic care and $c_{f}^{*}=0$. Hence, $c_{f}^{*}-\bar{c}_{f} \leq 0$ and the father does not suffer any cost associated with the social norm. Noting that $c_{m}+c_{p}=1$, the couple chooses child care private provision to maximize (1) where $x_{h \ell}=x_{m}+x_{f}=y+q$ because $p=y$. The optimal level of informal low-quality child care is thus implicitly determined by

$$
v^{\prime}\left(c_{h \ell}^{*}\right)=\beta v^{\prime}\left(1-c_{h \ell}^{*}\right) .
$$

First-order condition (2) indicates that traditional mothers provide informal basic care, $c_{h \ell}^{*}$, up to the point where marginal utility from informal care equals the marginal benefit from formal care, $1-c_{h \ell}^{*}$.

The marginal norm cost for traditional mothers, $\gamma_{m}$, does not enter the FOC (2); they do not suffer any norm cost because by definition we have $c_{h h}^{*}=0$ so that $c_{h \ell}^{*}>\bar{c}>c_{h h}^{*}=0$.

\footnotetext{
${ }^{9}$ Having only the mother in the high-career path is dominated by having both parents in the high-career path because the latter involves no norm costs for the father and higher future benefits. Similarly, having both parents entering the low-career path can never be optimal since then the couple forgoes future benefits $q_{f}$. As a result, the social norm for fathers is never binding in equilibrium.
} 
The optimal level of quality care, $d_{i}^{*}$, provided by the two parents is implicitly defined by:

$$
\rho_{i}(q) v_{d}^{\prime}\left(d_{i}\right)=v_{L}^{\prime}\left(\bar{L}-d_{i}\right), i=f, m .
$$

First-order condition (3) indicates that each parent provides quality care, $d_{i}$, up to the point where marginal utility from quality care equals its marginal cost in terms of leisure.

The indirect utility of this $h \ell$-couple as a function of informal basic and quality child care writes:

$$
\begin{aligned}
W_{h \ell}^{*} & =y+q+v\left(c_{h \ell}^{*}\right)+\beta v\left(1-c_{h \ell}^{*}\right)+\rho_{m}(q) v_{d}\left(d_{m}^{*}\right) \\
& +\rho_{f}(q) v_{d}\left(d_{f}^{*}\right)+v_{L}\left(\bar{L}-d_{m}^{*}\right)+v_{L}\left(\bar{L}-d_{f}^{*}\right)
\end{aligned}
$$

High-career couple. High-career couples have to buy the full amount of basic care in the market. Quality care is instead chosen again according to (3). Since $c_{f}^{*}=0$, the father does not suffer any cost associated with the social norm. As a result, the social norm for fathers is binding neither in traditional nor in career-couples. Thus, we can simplify the notation writing $\bar{c}_{m}=\bar{c}$ and $\gamma_{m}=\gamma$. High-career mothers suffer the cost from deviating from the norm and the couple's welfare amounts to:

$$
\begin{aligned}
W_{h h}^{*} & =y+q(1+\alpha)+\beta v(1)+\rho_{m}(q) v_{d}\left(d_{m}^{*}\right)+\rho_{f}(q) v_{d}\left(d_{f}^{*}\right) \\
& +v_{L}\left(\bar{L}-d_{m}^{*}\right)+v_{L}\left(\bar{L}-d_{f}^{*}\right)-\gamma \bar{c},
\end{aligned}
$$

where $d_{m}^{*}$ and $d_{f}^{*}$ are the same as in $W_{h \ell}^{*}$. Also note that high-career couples who exclusively have to rely on private basic child care are those with higher consumption levels, that is $x_{h \ell}^{*}=$ $y+q<x_{h h}^{*}=y+q(1+\alpha)$.

We are now in the position to analyze the couple's decision about the two partners' career paths. Families have to choose whether to be a high-career $h h$-couple fully relying of formal child care, or to be a traditional $h \ell$-couple where the mother provides some informal care. A couple will become a high-career couple if it is beneficiary to do so, that is if $W_{h h}^{*} \geq W_{h \ell}^{*}$, or if

$$
q \geq \hat{q}^{*} \equiv \frac{1}{\alpha}\left[v\left(c_{h \ell}^{*}\right)+\beta v\left(1-c_{h \ell}^{*}\right)-\beta v(1)+\gamma \bar{c}\right] .
$$

The marginal couple $\hat{q}^{*}$ is the couple where parents are indifferent between belonging to a traditional and to a career couple. Given $\hat{q}^{*}$ we can now define average informal basic child care in society:

$$
\bar{c}=\int_{0}^{\hat{q}^{*}} c_{h \ell}^{*} f(q) \mathrm{d} q=F\left(\hat{q}^{*}\right) c_{h \ell}^{*} .
$$

\subsection{Market outcome}

An allocation is fully described by the identity of the marginal couple, by the amount of informal basic care provided by traditional couples and by the amount of informal quality care provided 
by traditional and career couples. The following proposition characterizes the laissez-faire allocation.

Proposition 1 (Characterization of the market outcome) When mothers who do not provide basic child care suffer from deviating from the social norm, i.e. $\gamma>0$, and/or the job market suffers from gender discrimination, $\alpha<1$, then:

(i) it is never optimal for fathers to take up the low-career path;

(ii) the marginal couple is given by

$$
\left.\hat{q}^{*}=\frac{1}{\alpha}\left[v\left(c_{h \ell}^{*}\right)+\beta\left[v\left(1-c_{h \ell}^{*}\right)-v(1)\right]+\gamma F\left(\hat{q}^{*}\right) c_{h \ell}^{*}\right)\right],
$$

couples with future job opportunities higher or equal to the threshold $\hat{q}^{*}$ choose the highcareer path for both parents;

(iii) informal basic care provided by traditional mothers, $c_{h \ell}^{*}$, satisfies equation (2);

(iv) informal quality care provided by mothers and fathers, $d_{i}^{*}, i=f, m$, satisfies equation (3). It is relatively larger for mothers within couples and is increasing in $q$ across couples.

There are both traditional and career couples in the economy if $\hat{q}^{*} \in(0, Q)$. From (4), an interior solution requires that $\hat{q}^{*}$ exists such that $\hat{q}^{*}=(1 / \alpha)\left[v\left(c_{h \ell}\right)+\beta\left[v\left(1-c_{h \ell}\right)-v(1)\right]+\right.$ $\left.\gamma F\left(\hat{q}^{*}\right) c_{h \ell}\right]<Q$. Due to the concavity of $v, v\left(c_{h \ell}\right)+\beta\left[v\left(1-c_{h \ell}\right)-v(1)\right]>0$ holds so that the previous inequality is always met provided that $Q$ is sufficiently large and $F(\hat{q})$ is concave, which we assume in the remainder of the paper.

Point $(i v)$ of Proposition 1 indicates that mothers provide more informal quality care than fathers and the higher the career prospects the larger the level of informal quality care. As a result, career couples provide more informal quality care than traditional couples and, within both traditional and career couples, informal quality care increases with $q$.

The gender wage gap (GWG) is defined as the difference in total income earned by mothers and fathers in equilibrium and is given by:

$$
\begin{aligned}
G W G & =\int_{0}^{Q}[y+q] f(q) \mathrm{d} q-\left[F\left(\hat{q}^{*}\right) y\left(1-c_{h \ell}\right)+\int_{\hat{q}^{*}}^{Q}[y+\alpha q] f(q) \mathrm{d} q\right] \\
& =\underbrace{F\left(\hat{q}^{*}\right) c_{h \ell} y}_{\text {child penalty }}+\underbrace{\int_{0}^{\hat{q}^{*}} q f(q) \mathrm{d} q}_{\text {adverse sorting }}+\underbrace{\int_{\hat{q}^{*}}^{Q}(1-\alpha) q f(q) \mathrm{d} q}_{\text {plain discrimination }}
\end{aligned}
$$

The GWG decomposes in the gap between the hours worked because of family duties, and in the different return to labor supplied in sectors where man and women are employed. The first term in (5) thus represents "child penalty" (see Blau and Kahn 2017; Kleven et al. 2018): 
mothers in traditional couples do not work full time, but spend part of their time to provide informal basic care. Child penalty thus depends on average informal basic care, $\bar{c}=F\left(\hat{q}^{*}\right) c_{h \ell}$, provided by traditional mothers. The second term accounts for the fact that women forego the extra earning opportunities associated with the high-career path. Interestingly, both child penalty and "adverse sorting" are affected by social norms and child care decision through $\hat{q}^{*}$. They decrease when the share of career mothers in the society increases. The model thus offers a clean explanation of how social pressure determines women sorting and thus their low participation in leading positions together with lower wages. Finally, the last term in (5) captures the unexplained component of the GWG of the Oaxaca-Blinder decomposition, or the plain discrimination part; it vanishes when $\alpha=1$.

\subsubsection{Welfare analysis of the market outcome}

To characterize the inefficiency created by the social norm we consider now the (unweighted) sum of utilities of all households. An efficient or first-best $(f b)$ allocation is defined by the indifferent couple, $\hat{q}^{f b}$ (which determines the share of female participation in the high-career path), by the level of informal basic care chosen by traditional couples, $c_{h \ell}$ for $q<\hat{q}^{f b}$ (recall that, by definition, $c_{h h}^{f b}=0$ ) and by the level of quality care $d_{i}, i=f, m$.

Specifically, the efficient allocation $\left\{c_{h \ell}, d_{f}, d_{m}, \hat{q}\right\}$ maximizes the following welfare function:

$$
\begin{aligned}
S W= & \int_{0}^{\hat{q}}\left(y+q+\rho_{m}(q) v_{d}\left(d_{m}\right)+\rho_{f}(q) v_{d}\left(d_{f}\right)\right) f(q) \mathrm{d} q \\
& +\int_{\hat{q}}^{Q}\left(y+q(1+\alpha)+\rho_{m}(q) v_{d}\left(d_{m}\right)+\rho_{f}(q) v_{d}\left(d_{f}\right)\right) f(q) \mathrm{d} q \\
& +F(\hat{q})\left(v\left(c_{h \ell}\right)+\beta v\left(1-c_{h \ell}\right)\right)+(1-F(\hat{q}))(\beta v(1)-\gamma \bar{c})+v_{L}\left(\bar{L}-d_{m}\right)+v_{L}\left(\bar{L}-d_{f}\right)
\end{aligned}
$$

where $\bar{c}=F(\hat{q}) c_{h \ell}$.

The efficient level of informal basic care, $c_{h \ell}^{f b}$, is implicitly given by:

$$
v^{\prime}\left(c_{h \ell}\right)=\beta v^{\prime}\left(1-c_{h \ell}\right)+\left[1-F\left(\hat{q}^{f b}\right)\right] \gamma .
$$

The left-hand side denotes the social marginal benefit of informal basic care while the righthand side denotes the social marginal cost of formal care. Compared to the market outcome described in (2), the marginal benefit contains an additional term $\left[1-F\left(\hat{q}^{f b}\right)\right] \gamma$ which reflects the negative externality of informal basic care provision on type- $h h$ couples whose share is $1-F\left(\hat{q}^{f b}\right)$. Informal basic care is thus inefficiently high in the market outcome: $c_{h \ell}^{*}>c_{h \ell}^{f b}$.

Informal quality care is implicitly defined by the same FOC (3) and its level is thus efficient in the market outcome.

The FOC wrt $\hat{q}$ can be rewritten as:

$$
\hat{q}^{f b} \equiv \frac{1}{\alpha}\left\{\left[v\left(c_{h \ell}^{f b}\right)+\beta\left(v\left(1-c_{h \ell}^{f b}\right)-v(1)\right)\right]+\gamma F\left(\hat{q}^{f b}\right) c_{h \ell}^{f b}-\gamma\left[1-F\left(\hat{q}^{f b}\right)\right] c_{h \ell}^{f b}\right\}
$$


Comparing (4) and (8) and recalling that $c_{h \ell}^{*}>c_{h \ell}^{f b}$, we observe that $\hat{q}^{*}>\hat{q}^{f b}$, that is the share of high-career couples is inefficiently low in the market outcome.

To sum up, the negative externality generated by the social norm translates into overconsumption of informal basic care by traditional couples in the market outcome. This implies that the share of women entering the high-career path is inefficiently low. Concerning the GWG, in the market outcome both the child penalty and adverse sorting are inefficiently high. To see why consider that, for any given $q$, in the market outcome the female spouse's earnings are less than or equal to her first-best earnings. Indeed, child penalty is too high because women's labor income is too low due to the inefficiently high informal basic care $\left(c_{h \ell}^{*}>c_{h \ell}^{f b}\right)$. The optimal level of child penalty would thus be obtained when the negative externality exerted by traditional mothers on career mothers is properly taken into account. Finally, adverse sorting is inefficiently high because in families where $q \in\left[\hat{q}^{f b}, \hat{q}^{*}\right]$ women take the wrong decision of staying out of the high-career path and thus forgo the benefit from future prospects.

\section{Testing the model's implications}

The model yields the following testable predictions.

1 Mothers devote more time than fathers to both basic and quality informal care.

2 Time devoted to quality child care by both mothers and fathers is increasing in the family income.

3 Career mothers spend more time in the labor market than traditional mothers.

4 Time devoted to basic child care by mothers is decreasing in the family income.

About point 1, in the model the time devoted to basic care by career fathers and career mothers is zero by assumption because of the full-time working constraint. As a result only traditional mothers allocate time to basic informal child care. While both fathers and mothers devote time to quality informal care. As to Prediction 2 recall that, in the model, the higher the career prospects $q$ and the higher the utility parents receive from providing quality child care. This implies that informal quality care increases with the family's labor income. In addition, for any given level of $q$, mothers devote more time to informal quality care than their partners. Moving to Prediction 3, it translates into: high-income mothers spend more time in "market work" than low-income mothers. Finally, to be more specific about Prediction 4, in the model career mothers do not have time for basic informal care because they work full-time. Traditional mothers instead are flexible and are able to supplement formal care with some informal basic care. 
Before moving to time use data, observe that the most obvious proxy for career prospects, $q$, is the socio-economic status of the family. In what follows we will refer to $q$ as the parents' level of education.

\subsection{Data on time devoted to informal child care in Italy}

In a recent working paper, Barigozzi et al. (2019b) study how individuals of different gender, age, education and background allocate their time among several activities across a time span of more than 10 years (2002-2013) in Italy, analyzing data from the ISTAT "Use of Time" surveys. Pooling together three different cross-sections, they compare time use allocation in different time categories across specific socio-demographic groups, with a special focus on gender differences and their trends. To test the implications of the theoretical model presented in Section 2, in the current paper we resort to the most recent available Italian "Use of Time" survey, carried out in 2013, and consider the following time categories: informal child care, split up into basic and quality child care, household work and market work. For the description of the specific activities included in each time category and more information on the features of ISTAT time use data see Barigozzi et al. (2019b).

Sample selection The Italian "Use of Time" is a multi-member household survey collecting information on each member of the interviewed households. For consistency with our theoretical model, we restrict our sample to couples with at least one child under the age of 14 . This results in 4,622 observations, equally split between mothers and fathers. In our theoretical model, for the sake of simplicity, all mothers participate in the labor market. However, the share of non-employed mothers is very high in Italy and corresponds to almost $42 \%$ of mothers in our sample (see Table 1). To obtain representative results, we decided to include both employed and non-employed women in the sample. In terms of the theoretical model, non-employed mothers can be interpreted as those mothers with the highest flexibility in providing child care.

Table 2 reports some descriptive statistics of our sample and the average values of weekly time spent by parents in informal child care (Basic_child, Quality_child, Child_care = Basic_child + Quality_child ), household work, total household work (TOThousehold_work = basic_child + household_work) and market work. We created the category TOThousehold_work to account for the whole low-quality time devoted by parents to the family. For the sake of simplicity, household work is not considered in the theoretical model, but it represents a relevant component of the family burden (see below). Consequently, it is reasonable to associate household work and basic child care. Indeed household work can be done simultaneously with some basic child care (doing the cooking, cleaning and laundry and purchasing food while baby-sitting), whereas quality child care is not compatible with household work, and the two activities are mutually 
exclusive. Table 2 shows that the average time devoted to household work and market work by parents is basically the same: 18.91 and 18.83 hours per week, respectively. ${ }^{10}$ The average time devoted by parents to total child care is much lower, 7.49 hours per week, and is almost equally distributed between basic and quality child care: 3.96 and 3.53 hours per week, respectively.

In Table 3 and 4, we perform tests for the difference in group means for each time category. In Table 3, parents are grouped only by gender, without accounting for their educational level. On the contrary, in Table 4, parents are grouped by level of education, without taking into account their gender.

Table 3 confirms Prediction 1. Mothers devote slightly more time to quality care than fathers do (3.83 against 3.24 hours per week) and devote more than twice as much time to basic child care as fathers (5.68 a opposed to 2.25 hours per week). Overall, mothers devote roughly twice as much time to total informal care as fathers and this pattern is mainly driven by basic child care. Gender tests are highly significant for all the three categories of informal care: basic child care, quality child care, and for their sum.

The data presented in Table 4 show that Prediction 2 is also confirmed: time devoted to quality child care by parents is increasing in their education. More specifically, parents with a university degree devote almost one more hour per week to quality child care than less educated parents, and the difference is highly significant.

In Table 5 we group parents by both gender and education and thus consider four types of parents: fathers with high school or inferior degree; fathers with University degree; mothers with high school or inferior degree and mothers with University degree. This allows the gender gap to depend on education and vice versa. Let $k$ denote the time category, with $k$ belonging to the set \{quality child care, basic child care, total child care, household work, total household work, market work\}. We test for the gender and education gaps by means of a descriptive regression model, where time devoted to category $k$ is expressed as follows:

Time_spent_in_activity_k $=\alpha_{0 k}+\beta_{1 k}$ mother $+\beta_{2 k}$ University $+\beta_{3 k}$ Interaction $+\epsilon$.

For all observations $i=1, \ldots .4622$ in our sample, mother is a dummy taking value 1 if $i$ is a woman and 0 otherwise, University is a dummy taking value 1 if $i$ has a University degree and 0 otherwise, while Interaction represents the interaction of the two dummies, thus taking value 1 if $i$ is a woman and has a University degree.

Therefore, the values reported in Tables 5 corresponds to estimates of the following population parameters:

\footnotetext{
${ }^{10}$ The decimals refer to one additional weekly hour. For example, 7.55 hours per week amount to 7 hours and 33 minutes.
} 
- $\alpha_{0 k}$ : average time dedicated to category $k$ by a father with High School or inferior degree;

- $\alpha_{0 k}+\beta_{1 k}$ : average time dedicated to category $k$ by a mother with High School or inferior degree ;

- $\alpha_{0 k}+\beta_{2 k}$ : average time dedicated to category $k$ by a father with University degree;

- $\alpha_{0 k}+\beta_{1 k}+\beta_{2 k}+\beta_{3 k}$ : average time dedicated to category $k$ by a mother with University degree.

And the estimated gaps correspond to:

- $\beta_{1 k}$ : gender gap for parents with at most High School degree;

- $\beta_{1 k}+\beta_{3 k}$ : gender gap for parents with University degree;

- $\beta_{2 k}$ : education gap for fathers;

- $\beta_{2 k}+\beta_{3 k}$ : education gap for mothers.

The tests for the existence of these gaps (which amount to the tests for the difference in the group means) are reported in Table 5, which allows us to analyze Prediction 2 in more detail. From Table 5 we observe that the difference in hours devoted to quality care by fathers does not change much with education. Specifically, less educated fathers spend 3.17 hours per week in quality care versus 3.62 hours per week for more educated fathers, but the difference is not significant. Instead less educated mothers devote 3.66 hours per week to quality care versus 4.49 hours per week for more educated mothers, and this difference is highly significant. Hence we can conclude that the difference in time devoted to quality care by less and more educated parents displayed in Table 3 is totally driven by mothers' behaviors.

Moreover, Table 5 provides empirical evidence supporting Prediction 3: mothers with a university degree spend more time in "market work" than mothers without a university degree. Specifically, less educated mothers devote 10.65 hours per week to market work versus 13.52 hours per week for mothers with a University degree. The difference is only significant at a $5 \%$ level. Interestingly the opposite pattern seems true for fathers, since more educated fathers work less than their less educated counterpart, however the difference is not statistically significant.

Table 5 suggests that Prediction 4 is at odds with the data because more educated mothers spend more time in basic care than less educated mothers. The difference amounts to more than two hours per week and is highly significant. Note, however, that Prediction 4 becomes more consistent with the data if we account for the total amount of time that mothers devote to the household. Recall that "TOThousehold work" is the sum of time devoted to "basic_child" and "household_work". More educated women spend less time in "household_work" because they 
are more likely to purchase these services in the market (by employing a cleaning person, for example). The difference in household work by education amounts to almost 7 hours per week and is highly significant. By delegating to other people at least part of the household work, more educated mothers turn out to devote less time to the house and to the basic needs of their kids than less educated mothers. Indeed, less educated women devote 36.33 hours per week to "TOThousehold work" against 31.45 hours per week for more educated women. Thus, it is reasonable to rephrase Prediction 4 as follows:

4 (revisited) Total time devoted to basic child care and household work by mothers is decreasing in the family income.

As mentioned before, this pattern is totally driven by household work. However, basic child care provided by less educated mothers is likely to be understated because, when devoting time to household work, mothers can simultaneously take care of a child while reporting household work as their primary activity. From that perspective, we observe that the hours per week devoted by less educated mothers to household work (31.05) are more than 6 times the hours devoted to basic child care (5.27), confirming that baby-sitting at home is likely to overlap, at least in part, with mothers' household works. In addition, the gender gap in household work is very high and persists across different educational levels, a property which is consistent with Barigozzi et al. (2019b). Irrespective of the level of education, fathers devote about 8 hours per week to household work and, on average, the gender gap amounts to 21 hours per week (see Table 3).

Finally we provide some additional information on the sample of mothers that we consider. From Table 1 we observe that non-employed mothers belong to one of the following five categories: unemployed, housewives, students, retired and other. Housewives represent the largest category among the non-employed mothers and make up about $30 \%$ of the mothers subsample. The last row of Table 6 shows that about $25 \%$ of mothers in the whole sample have a university degree. Among these more educated mothers, about $81 \%$ are employed while among less educated mothers the percentage of employed drops to about $52 \%$, suggesting a strong association between having a university and employment. The non negligible share of less educated mothers who are not employed (and devote no time to market work) affects the average time mothers devote to work which is reported in Table 5. This indeed corresponds to an unconditional mean calculated for both employed and non-employed mothers. Our result on the education gap in mothers' market work is thus likely to be overestimated.

As a latest remark about Prediction 4 on time devoted to basic child care by mothers, note that school teachers enter as educated women in the Time Use survey, but they represent "traditional mothers" in our theoretical model because they have little or no career prospects, but benefit from large flexibility. In particular, Italian school teachers are able to provide informal 
basic care in the afternoon, after their classes. ${ }^{11}$ This is another reason why Prediction 4 , in its original formulation, does not appear to be consistent with the data.

\section{Conclusion}

We study couples' child care and career decisions. Basic child care can be provided informally or bought in the market. The total amount is given and imposed by the requirement that a small child needs constant care. For quality child care, on the other hand, spouses' contributions and the total level are endogenous. Parents trade off leisure against quality care, the benefits of which depend on their own career prospects/productivity. High career mothers suffer from a norm cost caused by "mothers' guilt". Through their basic child care choices low career mothers create a negative externality via the norm cost. Consequently, the laissez faire solution is inefficient; it implies too much informal child care and a share of high-career mothers which is too low.

Our theoretical model yields four main stylized facts which we confront with data from the ISTAT "Use of Time" most recent survey carried out in 2013. By using education as a proxy for the career prospects of couples, we find that three predictions from the model are confirmed by the data. In Italian families, $(i)$ mothers devote more time than fathers to both basic and quality informal care; (ii) time devoted to quality informal care by both mothers and fathers is increasing in education; (iii) time spent in the labor market by mothers increases with education. A forth prediction from the model, namely that basic informal care provided by mothers decreases in education, is not consistent with the data. We explain this incongruity by the fact that our theoretical model disregards time devoted by parents to household work which represents a relevant burden for mothers in Italy (an average of 29.68 hours per week against 8.13 hours per week for fathers) and mothers may provide household work when baby-sitting. Specifically, mothers can indicate household work as their first activity and baby-sitting as their secondary activity (but we only account for primary activity in this study). In addition, in Italy, about the $20 \%$ of employed and married women works as teachers in the Public Sector where workers are relatively flexible and have time to perform more basic informal care than other full-time workers. This has lead us to consider a revisited forth prediction of the model, namely that (iv) time devoted to basic informal care and household work by mothers is decreasing in the family income. We have show that this prediction is consistent with the data. This, in turn, is due to the fact that more educated mothers purchase some household work in the market.

\footnotetext{
${ }^{11}$ Unfortunately the survey does not allow us to know the percentage of school teachers among employed mothers in the sample. However, this percentage is likely to be important. Indeed, the $83 \%$ of Italian school teachers are women, the average in the OECD Countries being 68\%; see "Gender imbalances in the teaching profession", OECD (2017). And we know from Del Boca et al. (2000) that the $19 \%$ of Italian married and employed women was working as teacher in 1995 .
} 
To conclude, a gender gap in informal child care provision persists in Italian families (an average gap of 4 hours per week that increases with education) and a much stronger gender gap in household work still exists (with an average gap of 21.55 hours per week that decreases with education). Our theoretical model provides a possible explanation for such gaps based on a social norm on gender roles in the family and on a persisting gender inequality of opportunities in the labor market.

\section{References}

[1] Akerlof, G.A., and R.E. Kranton, "Economics and identity," The Quarterly Journal of Economics, 2000, 715-753.

[2] Akerlof, G.A., and R.E. Kranton, "Identity economics," The Economists' Voice, 2010, 7 (2), 1553-3832.

[3] Barigozzi, F., Cremer H., and K. Roeder, "Women's Career Choices, Social Norms and Child Care Policies," Journal of Public Economics, 2018, 168, 162-173.

[4] Barigozzi, F., Cremer H., and K. Roeder, "Having it all, for all: child-care subsidies and income distribution reconciled," TSE Working Paper, n. 19-1005, April 2019a.

[5] Barigozzi, F., C. Di Timoteo and C. Monfardini, "Italian Families in the 21st Century: an Analysis of Gender Gaps based on Time Diaries," mimeo, University of Bologna, 2019b.

[6] Bernal, R., "The effect of maternal employment and child care on children's cognitive development," International Economic Review, 2008, 49 (4), 1173-1209.

[7] Bertrand, M., Kamenica, E. \& Pan, J. "Gender identity and relative income within households," Quarterly Journal of Economics, 2015, 130, 571-614.

[8] Blau, F.D., and L.M. Kahn, "The gender wage gap: extent, trends, and explanations," Journal of Economic Literature, 2017, 55 (3), 789-865.

[9] Blinder, A., "Wage discrimination: reduced form and structural estimates," Journal of Human Resources, 1973, 8, 436-55.

[10] Bursztyn L., Fujiwara T. and Pallais A., "Acting wife': marriage market incentives and labor market investments," American Economic Review, 2017, 107 (11), 3288-3319.

[11] Del Boca, D., M. Locatelli and S. Pasqua, "Employment Decisions of Married Women: Evidence and Explanations," LABOUR, 2000, 14(1), 35-52. 
[12] Card, D., A.R. Cardoso, and P. Kline, "Bargaining, sorting, and the gender wage gap: quantifying the impact of firms on the relative pay of women," Quarterly Journal of Economics, 2016, 131 (2), 633-86.

[13] Chiappori, P.A., Salanié, B. \& Weiss, Y. "Partner choice, investment in children, and the marital college premium," American Economic Review, 2017, 107, 2109-2167.

[14] Ciccia, R., and M. Verloo, "Parental leave regulations and the persistence of the male breadwinner model: using fuzzy-set ideal type analysis to assess gender equality in an enlarged Europe," Journal of European Social Policy, 2012, 22(5), 507-528.

[15] Craig, L., "Does Father Care Mean Father Share? A Comparison of How Mothers and Fathers in Intact Families Spend Time with Children," Gender and Society, 2006, 20(2), 259-281.

[16] Doepke, M., G. Sorrenti, and F. Zilibotti, "The Economics of Parenting," Annual Review of Economics, 2019, 11(1). DOI: https://doi.org/10.1146/annurev-economics-080218030156.

[17] Fortin, N.M., "Gender role attitudes and the labour-market outcomes of women across OECD countries," Oxford Review of Economic Policy, 2005, 21(3), 416-438.

[18] Goldin, C., "The quiet revolution that transformed women's employment, education, and family," The American Economic Review, 2006, 96(2), 1-21.

[19] Goldin, C. "A grand gender convergence: its last chapter," American Economic Review, 2014, 104(4), 1091-119.

[20] Guendouzi, J., "'The guilt thing': balancing domestic and professional roles," Journal of Marriage and Family, 2006, 68(4), 901-909.

[21] Haas, L., C.P. Hwang, "Workplace support and European fathers' use of state policies promoting shared childcare," Community, Work \& Family, 2019, 22(1), 1-22.

[22] Huerta, M.d.C., W. Adema, J. Baxter, M. Corak, M. Deding, M.C. Gray, W.J. Han, and J. Waldfogel, "Early maternal employment and child development in five OECD countries," OECD Social, Employment and Migration Working Papers, 2011, 118.

[23] Kleven, H., and C. Landais, "Gender inequality and economic development: fertility, education and norms," Economica, 2017, 84, 180-209

[24] Kleven, H., C. Landais, and J.E. Søgaard, "Children and gender inequality: evidence from Denmark," American Economic Journal: Applied Economics, forthcoming, 2018. 
[25] Oaxaca, R., "Male-female wage differences in urban labor markets," International Economic Review, 1973, 14, 693-709.

[26] Paull, G., "Children and women's hours of work," The Economic Journal, 2008, 118, F8-F27.

[27] Rose, J., "Never enough hours in the day: employed mothers' perceptions of time pressure," Australian Journal of Social Issues, 2017, 52, 116-130.

[28] Rotkirch, A., and K. Janhunen, "Maternal guilt," Evolutionary Psychology, 2010, 8(1), 90-106.

[29] Yeung, W., J. Sandberg, P. Davis-Kean, and S. Hofferth, "Children's time with fathers in intact families," Journal of Marriage and Family, 2001, 63(1), 136-154.

\section{Appendix}

\section{A.1 Couples' optimization}

\section{A.1.1 Only the mother enters the high-career path}

Since the mother is in the high-career path, she is not able to take care of the children, and $c_{m}^{*}=0$. Hence, $\bar{c}_{m}-c_{h \ell}>0$ and the mother suffers the cost of not conforming to the norm. If the father provides some child care he suffers because of the norm too, so that here both social norms are potentially binding.

Welfare of this couple is denoted by $W_{\ell h}$. Noting that $c_{\ell h}+c_{p}=1$ and $p=y$, the couple chooses $c_{f}=c_{\ell h}, d_{m}$ and $d_{f}$ to maximize:

$$
\begin{aligned}
\max _{c_{\ell h}, d_{m}, d_{f}} \quad W_{\ell h} & =y+\alpha q+v\left(c_{\ell h}\right)+\beta v\left(1-c_{\ell h}\right)-\gamma_{f}\left(\max \left\{0 ; c_{\ell h}-\bar{c}_{f}\right\}\right)-\gamma_{m} \bar{c}_{m} \\
& +\rho_{m}(q) v_{d}\left(d_{m}\right)+\rho_{f}(q) v_{d}\left(d_{f}\right)+v_{L}\left(\bar{L}-d_{m}\right)+v_{L}\left(\bar{L}-d_{f}\right) .
\end{aligned}
$$

While the choice of $d_{m}$ and $d_{f}$ is as in the main text, optimal child care provision, $c_{\ell h}^{*}$, is implicitly determined by:

$$
v^{\prime}\left(c_{\ell h}^{*}\right)=\beta v^{\prime}\left(1-c_{h \ell}^{*}\right)+I \gamma_{f}
$$

where $I$ is an indicator function which takes value 1 when the social norm for fathers is binding, namely when $c_{\ell h}^{*}>\bar{c}_{f}$, and 0 otherwise.

Indirect welfare $W_{\ell h}^{*}$ writes:

$$
\begin{aligned}
W_{\ell h}^{*} & =y+\alpha q+v\left(c_{\ell h}^{*}\right)+\beta v\left(1-c_{\ell h}^{*}\right)-\gamma_{f}\left(\max \left\{0 ; c_{\ell h}^{*}-\bar{c}_{f}\right\}\right)-\gamma_{m} \bar{c}_{m} \\
& +\rho_{m}(q) v_{d}\left(d_{m}^{*}\right)+\rho_{f}(q) v_{d}\left(d_{f}^{*}\right)+v_{L}\left(\bar{L}-d_{m}^{*}\right)+v_{L}\left(\bar{L}-d_{f}^{*}\right) .
\end{aligned}
$$




\section{A.1.2 Both couples enter the low-career path}

Here again, if the father provides some child care, he suffers because he deviates from the norm. Both social norms are potentially binding. Welfare of this couple is denoted by $W_{\ell \ell}$. Noting that $c_{m}+c_{f}+c_{p}=1$ and $p=y$, the couple chooses $c_{\ell \ell}=c_{m}+c_{f}$ to maximize:

$$
\begin{aligned}
& \max _{c_{m}, c_{f}, d_{m}, d_{f}} W_{\ell \ell}=\left(1-c_{f}\right) y+\left(1-c_{m}\right) y-p\left(1-c_{\ell \ell}\right) \\
& +v\left(c_{\ell \ell}\right)+\beta v\left(1-c_{\ell \ell}\right)-\gamma_{f}\left(\max \left\{0 ; c_{\ell h}-\bar{c}_{f}\right\}\right)-\gamma_{m}\left(\max \left\{0 ; \bar{c}_{m}-c_{m}\right\}\right) \\
& +\rho_{m}(q) v_{d}\left(d_{m}\right)+\rho_{f}(q) v_{d}\left(d_{f}\right)+v_{L}\left(\bar{L}-d_{m}\right)+v_{L}\left(\bar{L}-d_{f}\right) \\
& =y+v\left(c_{\ell \ell}\right)+\beta v\left(1-c_{\ell \ell}\right)-\gamma_{f}\left(\max \left\{0 ; c_{\ell h}-\bar{c}_{f}\right\}\right)-\gamma_{m}\left(\max \left\{0 ; \bar{c}_{m}-c_{m}\right\}\right) \\
& +\rho_{m}(q) v_{d}\left(d_{m}\right)+\rho_{f}(q) v_{d}\left(d_{f}\right)+v_{L}\left(\bar{L}-d_{m}\right)+v_{L}\left(\bar{L}-d_{f}\right)
\end{aligned}
$$

The choice of $d_{m}$ and $d_{f}$ is again as in the main text, whereas optimal child care provision, $c_{\ell \ell}^{*}=c_{m}^{*}+c_{f}^{*}$, is implicitly determined by the two conditions:

$$
\begin{aligned}
v^{\prime}\left(c_{f}^{*}\right) & \leq \beta v^{\prime}\left(1-c_{\ell \ell}^{*}\right)+I \gamma_{f} \\
v^{\prime}\left(c_{m}^{*}\right) & \leq \beta v^{\prime}\left(1-c_{\ell \ell}^{*}\right)+I \gamma_{m}
\end{aligned}
$$

Welfare $W_{\ell \ell}^{*}$ now is:

$$
\begin{aligned}
W_{\ell \ell}^{*} & =y+v\left(c_{\ell \ell}^{*}\right)+\beta v\left(1-c_{\ell \ell}^{*}\right)-\gamma_{f}\left(\max \left\{0 ; c_{f}^{*}-\bar{c}_{f}\right\}\right)-\gamma_{m}\left(\max \left\{0 ; \bar{c}_{m}-c_{m}^{*}\right\}\right) \\
& +\rho_{m}(q) v_{d}\left(d_{m}^{*}\right)+\rho_{f}(q) v_{d}\left(d_{f}^{*}\right)+v_{L}\left(\bar{L}-d_{m}^{*}\right)+v_{L}\left(\bar{L}-d_{f}^{*}\right) .
\end{aligned}
$$




\section{TABLES}

TABLE 1: Distribution of Employment status of mothers in the sample.

\begin{tabular}{lrrr}
\hline Employment status & Frequency & Percent & Cum. \\
\hline 1-Employed & 1,332 & 57.64 & 57.64 \\
2-Unemployed & 268 & 11.60 & 69.23 \\
3-Housewife & 681 & 29.47 & 98.70 \\
4-Student & 4 & 0.17 & 98.87 \\
5-Retired & 18 & 0.78 & 99.65 \\
6-Other & 8 & 0.35 & 100.00 \\
\hline & & & \\
Observations & 2,311 & 100.00 & \\
\hline
\end{tabular}

TABLE 2: Descriptive statistics.

\begin{tabular}{lcccc}
\hline & Mean & $\begin{array}{c}\text { Standard } \\
\text { Dev }\end{array}$ & Min & Max \\
\hline Mother & 0.5 & 0.5 & 0 & 1 \\
Age 25-34 & 0.12 & 0.32 & 0 & 1 \\
Age 35-44 & 0.52 & 0.50 & 0 & 1 \\
Age 45-54 & 0.34 & 0.48 & 0 & 1 \\
Age 55-64 & 0.03 & 0.17 & 0 & 1 \\
University & 0.18 & 0.38 & 0 & 1 \\
\multicolumn{1}{c}{ Selected Time Categories* } & & & & 87.5 \\
Child_care & 7.49 & 9.91 & 0 & 51.1 \\
Quality_child & 3.53 & 5.9 & 0 & 72.1 \\
Basic_child & 3.96 & 7.03 & 0 & 90.3 \\
Household_work & 18.91 & 17.78 & 0 & 93.1 \\
TOThousehold_work & 22.87 & 19.88 & 0 & 129.5 \\
Market_work & 18.83 & 26.71 & 0 & \\
\hline Observations & & & 4,622 & \\
\hline
\end{tabular}

* The Mean of Time Categories variables is the average time spent per week, in hours.

Child_care $=$ Basic_child + Quality_child, TOThousehold_work $=$ Basic_child + Household_work 
TABLE 3: Time spent in selected time categories by gender.

\begin{tabular}{|c|c|c|}
\hline & & Average weekly time (hours) \\
\hline \multirow[t]{3}{*}{ Child_care } & Fathers & 5.48 \\
\hline & Mothers & 9.50 \\
\hline & GENDER-TEST & $\begin{array}{c}4.02 * * * \\
(0.227)\end{array}$ \\
\hline \multirow[t]{3}{*}{ Quality_child } & Fathers & 3.24 \\
\hline & Mothers & 3.83 \\
\hline & GENDER-TEST & $\begin{array}{c}0.59 * * * \\
(0.15)\end{array}$ \\
\hline \multirow[t]{3}{*}{ Basic_child } & Fathers & 2.25 \\
\hline & Mothers & 5.68 \\
\hline & GENDER-TEST & $\begin{array}{c}3.43 * * * \\
(0.167)\end{array}$ \\
\hline \multirow[t]{3}{*}{ Household_work } & Fathers & 8.13 \\
\hline & Mothers & 29.68 \\
\hline & GENDER-TEST & $\begin{array}{c}21.55^{* * *} \\
(0.399)\end{array}$ \\
\hline \multirow[t]{3}{*}{ TOThousehold_work } & Fathers & 10.37 \\
\hline & Mothers & 35.36 \\
\hline & GENDER-TEST & $\begin{array}{c}24.99 * * * \\
(0.439)\end{array}$ \\
\hline \multirow[t]{3}{*}{ Market_work } & Fathers & 26.45 \\
\hline & Mothers & 11.22 \\
\hline & GENDER-TEST & $\begin{array}{c}-15.23 * * * \\
(0.64)\end{array}$ \\
\hline Observations & & 4,622 \\
\hline
\end{tabular}

Gender test is the test of the difference in means between fathers and mothers. Clustered standard errors at the household level reported in parentheses.

$* * * p<0.01, * * p<0.05, * p<0.1$. 
TABLE 4: Time spent in selected categories by education.

\begin{tabular}{|c|c|c|c|}
\hline \multicolumn{4}{|c|}{ Average weekly time (hours) } \\
\hline & $\begin{array}{c}\text { High-School } \\
\text { or less }\end{array}$ & University & EDUC-TEST \\
\hline Child_care & 7.06 & 9.50 & $\begin{array}{c}2.44^{* * *} \\
(0.475)\end{array}$ \\
\hline Quality_child & 3.41 & 4.10 & $\begin{array}{c}0.70 * * * \\
(0.255)\end{array}$ \\
\hline Basic_child & 3.65 & 5.40 & $\begin{array}{c}1.75^{* * *} \\
(0.335)\end{array}$ \\
\hline Household_work & 19.30 & 17.11 & $\begin{array}{c}-2.19 * * * \\
(0.571)\end{array}$ \\
\hline TOThousehold_work & 22.95 & 22.51 & $\begin{array}{c}-0.44 \\
(0.672)\end{array}$ \\
\hline Market_work & 18.88 & 18.61 & $\begin{array}{c}-0.27 \\
(1.065)\end{array}$ \\
\hline Observations: & & 4,622 & \\
\hline
\end{tabular}

Education test is the test of the difference in means between High-School or lower degree and University degree. Clustered standard errors at the household level reported in parentheses.

$* * * p<0.01, * * p<0.05, * p<0.1$. 
TABLE 5: Time spent in selected categories by gender and education.

\begin{tabular}{|c|c|c|c|c|}
\hline \multicolumn{5}{|c|}{ Average weekly time (hours) } \\
\hline & & $\begin{array}{l}\text { High-School } \\
\text { or less }\end{array}$ & University & EDUC-TEST \\
\hline \multirow[t]{3}{*}{ Child_care } & Fathers & 5.27 & 6.64 & $\begin{array}{l}1.37^{* *} \\
(0.562)\end{array}$ \\
\hline & Mothers & 8.94 & 11.79 & $\begin{array}{c}2.85^{* * *} \\
(0.601)\end{array}$ \\
\hline & GENDER-TEST & $\begin{array}{c}3.67^{* * *} \\
(0.255)\end{array}$ & $\begin{array}{c}5.15^{* * *} \\
(0.621)\end{array}$ & \\
\hline \multirow[t]{3}{*}{ Quality_child } & Fathers & 3.17 & 3.62 & $\begin{array}{c}0.46 \\
(0.382)\end{array}$ \\
\hline & Mothers & 3.66 & 4.49 & $\begin{array}{c}0.83^{* * *} \\
(0.308)\end{array}$ \\
\hline & GENDER-TEST & $\begin{array}{c}0.49 * * * \\
(0.166) \\
\end{array}$ & $\begin{array}{l}0.87^{* *} \\
(0.421) \\
\end{array}$ & \\
\hline \multirow[t]{3}{*}{ Basic_child } & Fathers & 2.10 & 3.01 & $\begin{array}{c}0.91^{* * *} \\
(0.345)\end{array}$ \\
\hline & Mothers & 5.27 & 7.30 & $\begin{array}{c}2.03^{* * *} \\
(0.470)\end{array}$ \\
\hline & GENDER-TEST & $\begin{array}{c}3.17^{* * *} \\
(0.182)\end{array}$ & $\begin{array}{c}4.29 * * * \\
(0.469)\end{array}$ & \\
\hline \multirow[t]{3}{*}{ Household_work } & Fathers & 8.10 & 8.30 & $\begin{array}{c}0.21 \\
(0.619)\end{array}$ \\
\hline & Mothers & 31.05 & 24.15 & $\begin{array}{c}-6.90 * * * \\
(0.775)\end{array}$ \\
\hline & GENDER-TEST & $\begin{array}{c}22.96 * * * \\
(0.451)\end{array}$ & $\begin{array}{c}15.84^{* * *} \\
(0.829)\end{array}$ & \\
\hline \multirow[t]{3}{*}{ TOThousehold_work } & Fathers & 10.20 & 11.32 & $\begin{array}{c}1.12 \\
(0.748)\end{array}$ \\
\hline & Mothers & 36.33 & 31.45 & $\begin{array}{c}-4.88^{* * *} \\
(0.883)\end{array}$ \\
\hline & GENDER-TEST & $\begin{array}{c}26.13^{* * *} \\
(0.491)\end{array}$ & $\begin{array}{c}20.13^{* * *} \\
(0.986)\end{array}$ & \\
\hline \multirow[t]{3}{*}{ Market_work } & Fathers & 26.72 & 24.97 & $\begin{array}{c}-1.75 \\
(1.672)\end{array}$ \\
\hline & Mothers & 10.65 & 13.52 & $\begin{array}{l}2.87^{* *} \\
(1.119)\end{array}$ \\
\hline & GENDER-TEST & $\begin{array}{c}-16.07^{* * *} \\
(0.822)\end{array}$ & $\begin{array}{c}-11.46^{* * *} \\
(1.625)\end{array}$ & \\
\hline Obsevations & & & 4,622 & \\
\hline
\end{tabular}

Gender test is the test of the difference in mean between fathers and mothers. Education test is the test of the difference in mean between High-School or lower degree and University degree. Clustered standard errors at the household level reported in parentheses.

$* * * p<0.01, * * p<0.05, * p<0.1$. 
TABLE 6: Employment status of mothers in the sample by University degree.

\begin{tabular}{cccc}
\hline \multicolumn{5}{c}{ University Degree } \\
\hline \multirow{2}{*}{ Employed } & No & Yes & Total \\
\hline \multirow{2}{*}{ No } & 894 & 85 & 979 \\
& $(48.27 \%)$ & $(18.52 \%)$ & $(42.36 \%)$ \\
Yes & 958 & 374 & 1,332 \\
& $(51.73 \%)$ & $(81.48 \%)$ & $(57.64 \%)$ \\
\hline \multirow{2}{*}{ Total } & 1,852 & 459 & 2,311 \\
& $(100 \%)$ & $(100 \%)$ & $(100 \%)$ \\
\hline
\end{tabular}

